\title{
Consulting a Patient on Hormonal Contraception: A Clinical Case of Vulvar Vestibulitis
}

\author{
Olga Ya. Leshchenko*, MD, PhD \\ Scientific Centre for Family Health and Human Reproduction Problems \\ Irkutsk, the Russian Federation
}

\begin{abstract}
This article presents a clinical case of a 23 -year-old female who developed vulvodynia and dyspareunia while taking combined oral contraceptives (OCs). The case study shows that physicians should not recommend any combination of OCs over another to reduce weight gain, headache, breast tenderness, breakthrough bleeding, sexual dysfunction, dyspareunia, and decreased libido. Hormonal contraception counseling should be based on known, evidence-based recommendations and not be limited to the unnecessary substitution of one drug for another.(International Journal of Biomedicine. 2021;11(4):590-593.)
\end{abstract}

Key Words: vestibulodynia $\bullet$ vulvar vestibulitis $\bullet$ dyspareunia $\bullet$ hormonal oral contraceptives $\bullet$ pain

For citation: Leshchenko OYa. Consulting a Patient on Hormonal Contraception: A Clinical Case of Vulvar Vestibulitis. International Journal of Biomedicine. 2021;11(4):590-593. doi:10.21103/Article11(4)_CR1

\section{Introduction}

Modern hormonal contraception is generally an affordable, reversible, and highly effective family planning method. The frequency of sexual activity and sexual pleasure are positively correlated with satisfaction with contraception. OCs were not thought to improve sexual function in addition to reducing anxiety about the risk of unintended pregnancy. Few good quality studies report the effects of OC on female sexuality. The possible sexual side effects of OC are unknown to many patients and questionable to many physicians. Questions about the establishment of a causal relationship between the use of $\mathrm{OC}$ and sexual health continue to be relevant in clinical practice. ${ }^{(1)}$

Vulvar vestibulitis syndrome (VVS) is believed to be the leading cause of dyspareunia in premenopausal and postmenopausal women. Current epidemiological estimates suggest a prevalence in women of about $10 \%$. Gynecologists who cannot find an organic basis for vulvar pain often advise their patients to see a mental health professional. ${ }^{(2)}$

*Corresponding author: Olga Ya. Leshchenko, MD, PhD. Scientific Centre for Family Health and Human Reproduction Problems, Irkutsk, the Russian Federation.E-mail: loyairk@mail.ru
On the other hand, mental health professionals can make various assumptions about the nature of pain, ranging from the peculiarities of sexual technique to the somatization of the problem. Women become increasingly frustrated with an endless series of referrals and little pain relief.

\section{Case Presentation}

A 23-year-old woman, a law student, reported that she had consulted a large number of gynecologists without any positive effect on her recurrent dyspareunia. The woman, having started sexual activity at the age of 21 , immediately turned to the gynecologist for the selection of OC. Considering her complaints of severe acne on the face, chest, and back, the doctor recommended OC (Cyproteronum [2.0 mg] + Aethinyloestradiolum $[0.035 \mathrm{mg}])$. During the next year of taking this OC, the patient noted an improvement in the quality of the skin, which consisted in the almost complete disappearance of acne on all parts of the body and face, she also noted good tolerance of the contraceptive drug, stable weight, and regular menstruation after 28 days for 4-5 days which has become less painful. A year later, the patient again turned to a gynecologist for a scheduled preventive examination. The gynecologist recommended that she replace the current OC with another (Drospirenonum [3 mg] + Aethinyloestradiolum 
$[0.002 \mathrm{mg}]+$ Calcii levomefolas $[0.451 \mathrm{mg}])$, arguing that the previous OC contains a high dose of hormones and is not suitable for someone of a young age. The patient started taking the recommended drug. Bloody spotting, headache, and pain during intercourse appeared within the next 3 months of taking the new OC. The patient again turned to the gynecologist with these complaints. The doctor's recommendation was as follows: replace the second OC with a third OC (Drospirenonum [3 mg] + Aethinyloestradiolum [0.003 mg] + Calcii levomefolas [0.451 $\mathrm{mg}]$ ). In the next 2 months, the intermenstrual flow stopped, but the pain or discomfort during intercourse did not disappear. At this time, the patient notes that the insertion of the tampon has become much more inconvenient and painful than usual, and she abandoned tampons and switched to sanitary napkins. The patient experienced severe burning and cutting pain during penetration with each intercourse, although she noted arousal and readiness for sex. Despite this pain, she continued sexual intercourse, after which a burning sensation persisted during urination for the next 2 days. Then the patient turned to different gynecologists, who each time replaced her OC with another. Thus, within one year, 7 substitutions of $\mathrm{OC}$ were recommended to her. In parallel, the doctors periodically prescribed treatment for yeast infections with fluconazole preparations. Last time, the patient again turned to the gynecologist with previous complaints about the inability to live a sexual life due to painful sensations during intercourse, the lack of effectiveness of substitutions for OC, and the use of antifungal treatment. After a gynecological examination, the doctor announced to the patient that she did not have any objective abnormalities in the vagina and recommended that she consult a psychiatrist. The patient informed us that she had not had intercourse for several months due to severe pain during the penetration attempt. This pain often lasted for several hours after intercourse and intensified with urination. The pain did not occur if there was no pressure on the vulva, for example, intercourse, gynecological examination, or tampon insertion. The patient became afraid of pain and reported avoiding opportunities for relationships and sex; she also reported a marked decrease in sexual desire.

According to her somatic history, the patient was in excellent health and did not take any medication. She also provided me with an extensive set of test results and doctors' reports indicating that she did not have an infection, human papillomavirus, vulvovaginal disorder or disease, or any chronic disease or abnormal hormonal parameters. Gynecological examination with mirrors and colposcopy did not reveal any significant abnormalities. However, upon careful examination of the vulva and the vestibular zone of the entrance to the vagina, a shiny erythematous edematous mucosa attracted attention, and touching the vulvar mucosa with a gloved finger and a cotton swab caused the patient unbearable pain. Further, the patient was recommended to abolish hormonal contraception and at the same time to use Estriolum cream 1mg on the vulva 1 time per day for 3 weeks. At the end of this therapy, the patient reported that her pain had significantly decreased. After 2 months of observation, the patient decided to resume sexual activity, while she notes that the symptoms of vulvodynia practically do not bother her. The couple in this situation was asked to use a barrier method of protection.

\section{Discussion}

There are several scientific studies that have shown the relationship of OC with the development of dyspareunia, not only due to vaginal dryness, but also to the development of vestibulitis. ${ }^{(3-7)}$ The likelihood of superficial pain during intercourse appears to be higher when OCs are first used at a young age, and increases with duration of use. ${ }^{(4-6)} \mathrm{A}$ study of Israeli women taking OC showed that $51 \%$ of them use low doses of estrogen ( $\leq 20 \mathrm{mcg}$ ) and $49 \%$ use higher doses of estrogen $(30-35 \mathrm{mcg})$. Of the 132 women in the study, $86(65 \%)$ used OC: $68(79 \%)$ used low doses of estrogen $(P<0.002)$ compared to the general population), while only 18 (21\%) used higher doses of estrogen $(P<0.002$ compared to the general population). The authors conclude that significantly more patients with SVS use low doses of estrogen than those who use high doses of estrogen. ${ }^{(5)}$

In gynecology, the traditional diagnostic strategy for chronic dyspareunia is to look for organic causes and, in their absence, suggest a psychogenic etiology. In fact, there are no reliable organic diagnostic markers of VVS, and a routine gynecological examination does not imply a thorough examination of the vestibule of the vulva. ${ }^{(8)}$ Interestingly, psychiatric nosologies are similar to gynecological ones and also define dyspareunia in terms of an organic/psychogenic dichotomy. Again, this position ignores the localization of pain. As a result, dyspareunia without an organic cause is determined by the activity that it interferes with, that is, sexual intercourse.

There are the following criteria for VVS: 1) severe pain on vestibular touch or attempt at vaginal entry; 2) sensitivity to pressure localized on the eve of the vulva; 3 ) vestibular erythema of varying degrees. ${ }^{(8)}$ The diagnosis is usually based on the woman's report of pain during penile penetration and is confirmed by palpation of a cotton swab on the vestibule of the vulva. Approximately $90 \%$ of women ultimately diagnosed with VVS describe their pain with adjectives such as "burning" or "cutting pain." ${ }^{\prime(9)}$ Patients also usually describe their pain starting from the moment the penis enters the vagina. This pain can be reproduced by a gynecologist palpating the vestibule of the vulva with a cotton swab. This palpation is usually perceived as light pressure, but is extremely painful for women with VVS. Visual or colposcopic examinations of the vulva are not helpful in diagnosing VVS. On the other hand, there are numerous urogenital infections and dermatological conditions, the symptoms of which coincide with those of VVS..$^{(10-13)}$ There is also evidence indicating that VVS is difficult to distinguish from vaginismus. ${ }^{(14,15)}$ Finally, there are a number of chronic pain syndromes of the vulva or genitourinary system, called essential or dysesthetic vulvodynia, in patients who experience pain during intercourse and a positive cotton swab test. Usually, these patients are easily distinguished from women with VVS in that their pain is not limited to external stimulation, but occurs spontaneously over long periods of time and often on a daily basis. ${ }^{(16)}$ There is a very long list of proposed etiological factors and mechanisms for the development of VVS; however, this list is not accompanied by evidence-based randomized trials. ${ }^{(14)}$ There are currently several weakly evidence-based findings: 
1. SVS appears to be associated with the use of OCs containing a low dose of estrogen. ${ }^{(17)}$

2. There may be local vestibular changes, reflecting increased inflammation or increased nerve innervation. ${ }^{(18)}$

3. There is evidence of a possible genetic predisposition to VVS associated with the gene for interleukin-1 receptor antagonist (IL-1Ra), which is involved in inflammatory processes. ${ }^{(19)}$

4. Hypertonicity of the pelvic floor muscles is associated with urogenital pain. ${ }^{(20)}$

TheAmerican College ofObstetricians and Gynecologists proposed an algorithm for the treatment of VVS, starting with conservative treatment and gradually moving to more invasive interventions. Interestingly, there is no randomized controlled evidence to support any of the proposed interventions. ${ }^{(21)}$ In fact, there have been three randomized controlled trials that investigated medical interventions using cromolyn cream and fluconazole (showing ineffectiveness), ${ }^{(22,23)}$ and topical estrogen and testosterone with good clinical results. ${ }^{(24-26)}$ There are also two randomized controlled trials that have documented the effectiveness of non-medical approaches, such as cognitive behavioral therapy and biofeedback/pelvic floor physiotherapy and vestibulectomy. ${ }^{(27)}$

A recent review by Coelho et al. emphasized that OCs were associated with dyspareunia, not only due to possible vaginal dryness, but also due to the risk of vestibulitis. ${ }^{(1)}$ Several studies indicate a link between OC use and vestibular pain. ${ }^{(3-7)}$ The likelihood of superficial pain during intercourse appears to be higher when OCs are first used at a young age, and increases with duration of use. ${ }^{(4-6)}$ Other authors also reported that the use of OC containing $20 \mathrm{mg}$ of ethinyl estradiol was a risk factor for the development of vestibulodynia. ${ }^{(6,28)}$ Most international clinical guidelines believe that "Physicians should not recommend any combination of OC over another to reduce weight gain, headache, breast tenderness, breakthrough bleeding, mood disorders, acne, nausea, and decreased libido. There are no significant differences between the compositions." ${ }^{(29)}$ Long-term adverse symptoms are often alleviated by changes in $\mathrm{OC}$; however, none of the OCs have been proven to be superior in terms of side effects.(30) With a decrease in libido, it is necessary to reassure the patient that this problem will disappear over time, otherwise, consider increasing the dose of estrogen if the current dose is low. ${ }^{(30,31)}$ The adverse effects of OCs usually decrease to acceptance levels with continued use of the same drug. Physician reassurances that symptoms are likely to resolve within three to five months are often the only treatment needed. ${ }^{(32)}$

\section{Conclusion}

Dyspareunia due to VVS is a fairly commonly misdiagnosed problem. The previously mentioned categorical classification systems capture the complex relationships between genital pain, sexual interference, fear of penetration, muscle tension, and emotional stress. Failure to assess and adequately address this problem is of great importance for the quality of life of women and their partners. It might be better to think of the problem as a chronic pain disorder rather than sexual dysfunction, as this focuses clinical and research attention on a central symptom of pain. Studies of adverse sexual effects in women using OCs are controversial and require further research, but advice on oral hormonal contraception should be based on known evidence-based recommendations and not be limited to the unreasonable substitution of one $\mathrm{OC}$ for another.

\section{Acknowledgments}

This article contains material that has been discussed at the VIII International Research and Practical Conference «FUNDAMENTAL AND APPLIED ASPECTS OF REPRODUCTION» (December 2021, Irkutsk, Russia). The author thanks all researchers who participated in the oral discussion.

\section{References}

1. de Castro Coelho F, Barros C. The Potential of Hormonal Contraception to Influence Female Sexuality. Int J Reprod Med. 2019 Mar 3;2019:9701384. doi: 10.1155/2019/9701384. 2. Harlow BL, Wise LA, Stewart EG. Prevalence and predictors of chronic lower genital tract discomfort. Am J Obstet Gynecol. 2001 Sep;185(3):545-50. doi: 10.1067/ mob.2001.116748.

3. Bazin S, Bouchard C, Brisson J, Morin C, Meisels A, Fortier M. Vulvar vestibulitis syndrome: an exploratory casecontrol study. Obstet Gynecol. 1994 Jan;83(1):47-50.

4. Bouchard C, Brisson J, Fortier M, Morin C, Blanchette C. Use of oral contraceptive pills and vulvar vestibulitis: a casecontrol study. Am J Epidemiol. 2002 Aug 1;156(3):254-61. doi: 10.1093/aje/kwf037.

5. Greenstein A, Ben-Aroya Z, Fass O, Militscher I, Roslik Y, Chen J, Abramov L. Vulvar vestibulitis syndrome and estrogen dose of oral contraceptive pills. J Sex Med. 2007 Nov;4(6):1679-83. doi: 10.1111/j.1743-6109.2007.00621.x.

6. Berglund AL, Nigaard L, Rylander E. Vulvar pain, sexual behavior and genital infections in a young population: a pilot study. Acta Obstet Gynecol Scand. 2002 Aug;81(8):738-42. doi: 10.1034/j.1600-0412.2002.810809.x.

7. Bohm-Starke N, Johannesson U, Hilliges M, Rylander E, Torebjörk E. Decreased mechanical pain threshold in the vestibular mucosa of women using oral contraceptives: a contributing factor in vulvar vestibulitis? J Reprod Med. 2004 Nov;49(11):888-92.

8. Friedrich EG Jr. Vulvar vestibulitis syndrome. J Reprod Med. 1987 Feb;32(2):110-4.

9. Bergeron S, Binik YM, Khalifé S, Pagidas K, Glazer HI. Vulvar vestibulitis syndrome: reliability of diagnosis and evaluation of current diagnostic criteria. Obstet Gynecol. 2001 Jul;98(1):45-51. doi: 10.1016/s0029-7844(01)01389-8.

10. van der Meijden WI, Boffa MJ, Ter Harmsel WA, Kirtschig G, Lewis FM, Moyal-Barracco M, Tiplica GS, Sherrard J. 2016 European guideline for the management of vulval conditions. J Eur Acad Dermatol Venereol. 2017 Jun;31(6):925-941. doi: 10.1111/jdv.14096.

11. Harlow BL, Wise LA, Stewart EG. Prevalence and predictors of chronic lower genital tract discomfort. Am J Obstet Gynecol. 2001 Sep;185(3):545-50. doi: 10.1067/ mob.2001.116748. 
12. Foster DC. Vulvar disease. Obstet Gynecol. 2002 Jul;100(1):145-63. doi: 10.1016/s0029-7844(02)02080-х. 13. Kungurtseva EA, Popkova SM, Leschenko OY. [Reciprocal formation of mucosal microflora of open cavities of different habitats in women as an important factor of their reproductive health]. Vestn Ross Akad Med Nauk. 2014;(9-10):27-32. doi: 10.15690/vramn.v69i9-10.1128. [Article in Russian].

14. de Kruiff ME, ter Kuile MM, Weijenborg PT, van Lankveld JJ. Vaginismus and dyspareunia: is there a difference in clinical presentation? J Psychosom Obstet Gynaecol. 2000 Sep;21(3):149-55. doi: 10.3109/01674820009075622.

15. Meana M, Binik YM, Khalife S, Cohen DR. Biopsychosocial profile of women with dyspareunia. Obstet Gynecol. 1997 Oct;90(4 Pt 1):583-9. doi: 10.1016/s00297844(98)80136-1.

16. Bergeron S, Binik YM, Khalifé S, Pagidas K. Vulvar vestibulitis syndrome: a critical review. Clin J Pain. 1997 Mar;13(1):27-42. doi: 10.1097/00002508-199703000-00006. 17. Bouchard C, Brisson J, Fortier M, Morin C, Blanchette C. Use of oral contraceptive pills and vulvar vestibulitis: a casecontrol study. Am J Epidemiol. 2002 Aug 1;156(3):254-61. doi: 10.1093/aje/kwf037.

18. Bohm-Starke N, Hilliges M, Blomgren B, Falconer C, Rylander E. Increased blood flow and erythema in the posterior vestibular mucosa in vulvar vestibulitis(1). Obstet Gynecol. 2001 Dec;98(6):1067-74. doi: 10.1016/s0029-7844(01)01578-2. 19. Witkin SS, Gerber S, Ledger WJ. Differential characterization of women with vulvar vestibulitis syndrome. Am J Obstet Gynecol. 2002 Sep;187(3):589-94. doi: 10.1067/ mob.2002.125889.

20. Glazer HI, Rodke G, Swencionis C, Hertz R, Young AW. Treatment of vulvar vestibulitis syndrome with electromyographic biofeedback of pelvic floor musculature. J Reprod Med. 1995 Apr;40(4):283-90.

21. ACOG educational bulletin. Vulvar nonneoplastic epithelial disorders. Number 241, October 1997 (Replaces no. 139, January 1990). American College of Obstetricians and Gynecologists. Int J Gynaecol Obstet. 1998 Feb;60(2):181-8. 22. Nyirjesy P, Sobel JD, Weitz MV, Leaman DJ, Small MJ, Gelone SP. Cromolyn cream for recalcitrant idiopathic vulvar vestibulitis: results of a placebo controlled study. Sex Transm Infect. $2001 \mathrm{Feb}$;7(1):53-7. doi: 10.1136/sti.77.1.53.

23. Bornstein J, Livnat G, Stolar Z, Abramovici H. Pure versus complicated vulvar vestibulitis: a randomized trial of fluconazole treatment. Gynecol Obstet Invest. 2000;50(3):1947. doi: $10.1159 / 000010309$.

24. Burrows LJ, Goldstein AT. The treatment of vestibulodynia with topical estradiol and testosterone. Sex Med. 2013 Aug;1(1):30-3. doi: 10.1002/sm2.4.

25. Leshchenko O. Vaginal estriol and injections of autoplasma reduce the symptoms of vulvovaginal atrophy. MATURITAS. 2019;124:152. doi: 10.1016/j.maturitas.2019.04.120.

26. Leshchenko O, Atalyan A. Vaginal estriol and injections of autoplasma (plasmolifting) reduce the symptoms of vulvovaginal atrophy Journal of Lower Genital Tract Disease. 2017;21(2 S1):46.

27. Bergeron S, Binik YM, Khalifé S, Pagidas K, Glazer HI, Meana M, Amsel R. A randomized comparison of group cognitive--behavioral therapy, surface electromyographic biofeedback, and vestibulectomy in the treatment of dyspareunia resulting from vulvar vestibulitis. Pain. 2001 Apr;91(3):297-306. doi: 10.1016/S0304-3959(00)00449-8.

28. Edgardh K, Abdelnoor M. Vulvar vestibulitis and risk factors: a population-based case-control study in Oslo. Acta Derm Venereol. 2007;87(4):350-4. doi: 10.2340/000155550250 .

29. Moreau C, Trussell J, Gilbert F, Bajos N, Bouyer J. Oral contraceptive tolerance: does the type of pill matter? Obstet Gynecol. 2007 Jun;109(6):1277-85. doi: 10.1097/01. AOG.0000260956.61835.6d.

30. Sabatini R, Cagiano R. Comparison profiles of cycle control, side effects and sexual satisfaction of three hormonal contraceptives. Contraception. 2006 Sep;74(3):220-3. doi: 10.1016/j.contraception.2006.03.022.

31. Schaffir J. Hormonal contraception and sexual desire: a critical review. J Sex Marital Ther. 2006 Jul-Sep;32(4):305-14. doi: 10.1080/00926230600666311.

32. Grossman Barr N. Managing adverse effects of hormonal contraceptives. Am Fam Physician. 2010 Dec 15;82(12):1499-506. 